\title{
Paraplegia
}

\section{Anterior Plating of Unstable Cervical Spine Fractures}

\author{
D. C. Mann, MD, ${ }^{1}$ B. W. Bruner, MD, ${ }^{1}$ J. S. Keene, $M D,{ }^{1}$ A. B. Levin, MD $^{2}$ \\ ${ }^{1}$ Division of Orthopedic Surgery, ${ }^{2}$ Department of Neurosurgery, University of Wisconsin \\ Hospital and Clinics, 600 Highland Avenue, Madison, WI 53792, USA
}

\section{Summary}

Medical records and radiographs of 16 patients who had anterior decompression, bone grafting, and plating of grade III and IV (Allen 1982) unstable cervical spine injuries were reviewed. Surgery was performed within 15 days of injury, reductions were achieved and maintained at follow-up, and fusion occurred in all cases. Neurologic function stabilised or improved in all cases. However, 3 patients (19\%) had complications that necessitated additional surgery: one patient with undiagnosed non-contiguous posterior instability, and 2 patients for broken plates. These complications, in retrospect, could have been avoided.

Key words: Cervical spine; Fractures; Anterior bony fusion; Plate fixation

Anterior cervical decompression and fusion, popularised by Robinson (1958), Cloward (1958), and Bailey (1960) for the treatment of disc disease, has also been used to treat unstable fractures of the cervical spine. However, studies comparing this technique with posterior procedures show that anterior decompression and fusion has a higher incidence of complications (Bedbrook, 1966; Cheshire, 1969; Meyers, 1967; Stauffer, 1977; Van Peteghem 1979). Two prior studies have documented a low incidence of graft displacement or late kyphosis, but they included only a limited number of patients with unstable injuries (Cloward, 1969; Meyers, 1967). Three subsequent studies of failed anterior interbody fusions demonstrated a high incidence of graft dislodgement and late kyphosis (Stauffer, 1977; Bohler, 1980; Van Peteghem, 1979), but in those studies, the grafts had either no or only minimal internal fixation. Use of current internal fixation has reduced the incidence of late graft dislodgement and kyphosis (de Oliveira, 1987; Brown, 1988; Cabanela, 1988).

Correspondence to: Dr. David Mann, University of Wisconsin Hospitals and Clinics, Division of Orthopedic Surgery, 600 Highland Avenue, Madison, WI 53792, USA.

Read in part at: American Spinal Injury Association, Annual Meeting, Las Vegas, Nevada, April 3, 1989. 
However, in the studies cited above, injuries were not classified in terms of stability and results were not based on measurements of the post-operative radiographs. In this study, strict radiographic criteria were used to evaluate the quality and maintenance of the reductions achieved; injuries were strictly classified (Allen, 1982) and only unstable (grade III-IV) fractures were included.

\section{Materials and Methods}

Between 1979 and 1986, 25 patients with anterior decompression and spinal plating of unstable fractures of the cervical spine at our hospital were reviewed. All surgeries were performed by one of the authors $(\mathrm{ABL})$, and the results were reviewed independently by the other authors. Of these 25 patients, 3 died within 3 weeks of their injury, none directly related to the surgery, ( 2 from sepsis and 1 from disseminated intravascular coagulopathy) and 6 had less than 3 months follow-up, and thus, 16 patients were the basis for this study.

The average age of the patients was 26 years (range, 16-52 years) and average follow-up was 10 months ( 3 months-5 years). The cause of injury was: diving in 7 patients; motor vehicle accidents in 6; falls in 2; and a farm accident in 1 patient. The neurologic status of the patients on admission to the hospital was: no deficit in 4 ; quadriplegia in 4; incomplete neurologic syndrome in 4; and single nerve root

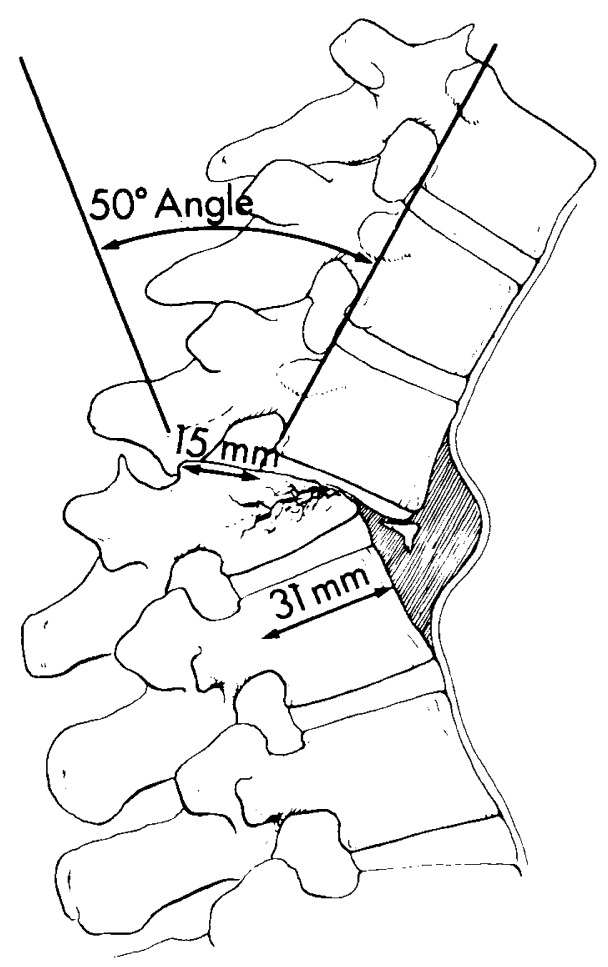

Figure 1 Diagrams of measurement for displacement percentage and angle of deformity. Refer to text for details. 
radiculopathies in 4. Patients with neurologic deficit were treated with Gardnerwells tongs until the spine was stabilised. The involved motion segment (level of injury) was $\mathrm{C} 3-4$ in 3 ; $\mathrm{C} 4-5$ in 5 ; $\mathrm{C} 5-6$ in 7 . In 1 patient, two motion segments (C4-C5-C6) were injured.

Radiographs obtained at the time of admission were reviewed, and the injuries were classified according to Allen et al. (1982). Based on Allen's criteria, there were 6 compression flexion injuries, 9 distractive flexion injuries, and 1 distractive extension injury. The injuries were also staged according to Allen's critiera: The 6 compressive flexion injuries were stages IV (3 patients) or $\mathrm{V}$ ( 3 patients); the 9 distractive flexion injuries were stages I ( 1 patient), II ( 1 patient), III ( 2 patients) or IV ( 5 patients); and the 1 distractive extension injury was stage II. All of these stages are considered to be unstable by Allen's criteria (Allen et al. 1982).

Radiographic evaluation included measurements of the angle of deformity and the displacement percentage, as described by Dickson et al., in 1978 (Fig. 1), and measurements of vertebral tilt and displacement, as described by White $e t$ al. in 1976 (Fig. 2A and 2B). These measurements were made on the pre-operative, immediate post-operative, and final follow-up radiographs.

Between 1979 and 1986, anterior decompression and plating was used exclusively for unstable cervical spine injuries because of the earlier experience by the operating surgeon in which retropulsed disc material and bone, not evident on pre-operative CT scans or myelograms, were found at surgery.

Surgery was performed as soon as the patient's condition was physiologically stable, and on average was done 15 days after injury (range 5-21 days). The average

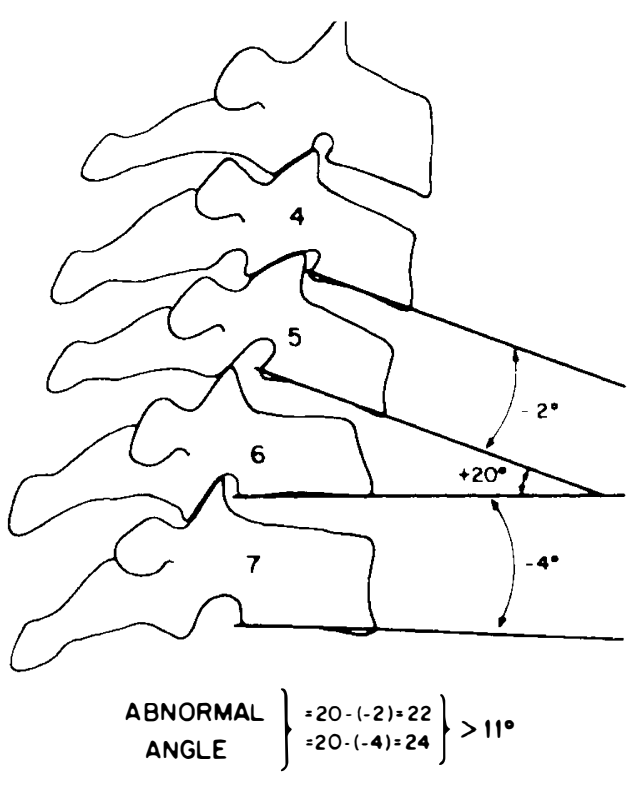

A

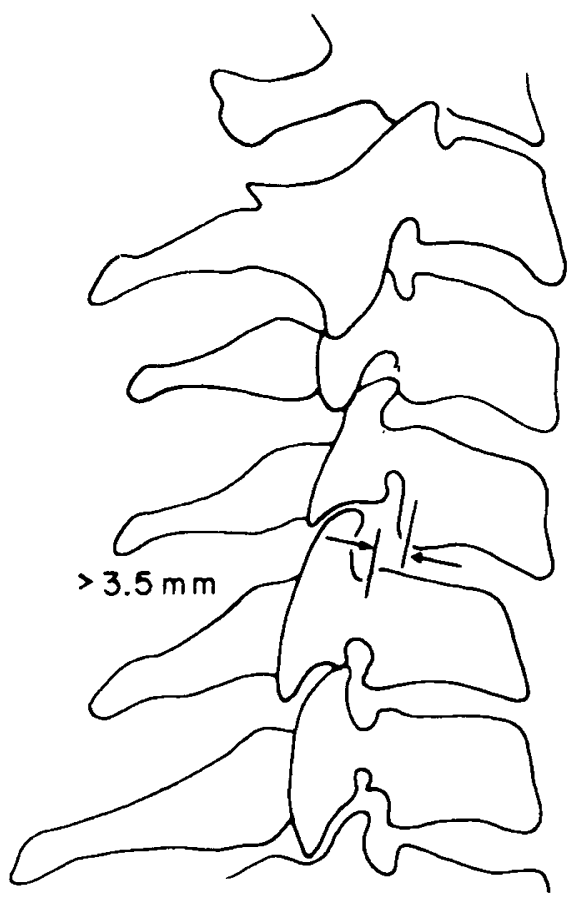

B

Figure 2A and 2B Diagrams showing measurement of tilt and displacement. Refer to text for details. 
operation time was 136 minutes (range 115-163 minutes) and average operative blood loss was $163 \mathrm{ml}$ (range 130-192 ml). In all cases, surgery was performed by one neurosurgeon $(\mathrm{ABL})$ according to the technique described by Cloward (1958). Autogenous iliac bone grafts were used in all cases. The grafts were keyed in place, as a rectangular strut or countersunk as a bone plug. Plate fixation was limited to one motion segment (two vertebral levels) in 9 patients, and spanned two motion segments (three vertebral levels) in 7 patients because of severe comminution of the vertebral body. Decompression was performed at the time of surgery, and 12 patients $(75 \%)$ had disruption of the posterior longitudinal ligament and retropulsed disc material and bone fragments in the spinal canal. In 4 of these cases with retropulsed disc material or bone fragments, the pre-operative CT scan and/or the myelogram did not demonstrate this pathology. In the 4 patients where the posterior longitudinal ligament was intact, no attempt was made to expose the spinal cord.

During the time period encompassed by this study various types of stainless steel plates were employed: Dynamic compression plates (1979-1983); Synthes multifragment plates (1983-1985); and Synthes cervical H-plates (1985-1986). With each type of plate, the screws were inserted to a depth that did not violate the posterior cortex of the vertebral body.

Post-operatively, patients were immobilised for 2 to 4 months in a Philadelphia collar and in a soft cervical orthosis for an additional 1 to 2 months, until free of pain.

\section{Results}

\section{Radiographic measurements}

At surgery, vertebral body displacement was improved from an initial deformity of $4.4 \mathrm{~mm}$ (sd $\pm 2.7 \mathrm{~mm}$ ) to $1.6 \mathrm{~mm}( \pm 1.2 \mathrm{~mm}$ ) (Table I). Mean displacement at the final follow-up was $1.9 \mathrm{~mm}( \pm 1.7 \mathrm{~mm})$, a loss of only $0.3 \mathrm{~mm}$ of correction. However, 2 patients lost more than $2.0 \mathrm{~mm}$ of correction by the time of the final follow-up exam.

Tilt angle was corrected from an initial deformity of $17 \cdot 3^{\circ}$ (sd $\pm 12 \cdot 3^{\circ}$ ) to $2 \cdot 4^{\circ}$ $\left( \pm 7 \cdot 0^{\circ}\right)$ at the time of surgery. Mean tilt angle at final follow-up was $4 \cdot 9^{\circ}\left( \pm 5 \cdot 3^{\circ}\right)$. Two patients lost more than $5^{\circ}$ of correction, and had $8^{\circ}$ and $10^{\circ}$ at final follow-up.

Table I Radiographic measurements

\begin{tabular}{|c|c|c|c|c|}
\hline & Pre-operative & Post-operative & Follow-up & $\begin{array}{l}\text { Follow-up } \\
\text { Post-operative }\end{array}$ \\
\hline Displacement & & & & \\
\hline$\underset{\text { Tilt }}{ } \mathrm{x} \pm$ s.d. (mm) & $4 \cdot 44 \pm 2 \cdot 71$ & $1 \cdot 63 \pm 1 \cdot 20$ & $1.94 \pm 1.69$ & $0 \cdot 31 \pm 1 \cdot 78$ \\
\hline $\begin{array}{l}\quad x \pm \text { s.d. (degrees) } \\
\text { Angle of Deformity }\end{array}$ & $17 \cdot 31 \pm 12 \cdot 25$ & $2 \cdot 38 \pm 7 \cdot 04$ & $4 \cdot 87 \pm 5 \cdot 33$ & $2 \cdot 49 \pm 3 \cdot 61$ \\
\hline $\begin{array}{l}x \pm \text { s.d. (degrees) } \\
\text { Displacement } \%\end{array}$ & $7 \cdot 69 \pm 7 \cdot 01$ & $3 \cdot 13 \pm 3 \cdot 50$ & $3 \cdot 13 \pm 3 \cdot 54$ & $0.0 \pm 4.97$ \\
\hline $\mathbf{x} \pm$ s.d. (percentage) & $19 \cdot 3 \pm 11 \cdot 87$ & $8 \cdot 00 \pm 6 \cdot 61$ & $8 \cdot 69 \pm 7 \cdot 64$ & $0 \cdot 69 \pm 9 \cdot 10$ \\
\hline
\end{tabular}


The angle of deformity was corrected from $7 \cdot 7^{\circ}\left(\mathrm{sd} \pm 7 \cdot 0^{\circ}\right)$ to a post-operative and follow-up angle of $3 \cdot 1^{\circ}\left( \pm 3 \cdot 5^{\circ}\right)$. In 2 patients, the angle of deformity increased to $7^{\circ}$ and $13^{\circ}$, respectively, by the time of final follow-up exam.

Displacement percentage was improved at surgery from $19 \cdot 3 \%$ (sd \pm 11.9 ) to $8 \cdot 0 \%( \pm 6 \cdot 6)$. At the final follow-up, average displacement was $8 \cdot 7 \%( \pm 7 \cdot 6)$. In 4 of the 16 patients, displacement percentage had increased to more than $9 \%$ (Table I).

\section{Complications}

Twelve patients had no complications and $4(25 \%)$ had complications related to the

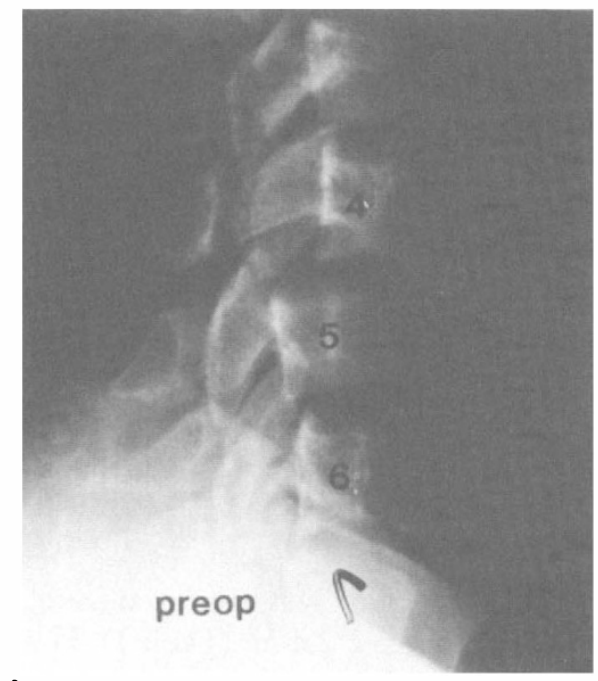

A

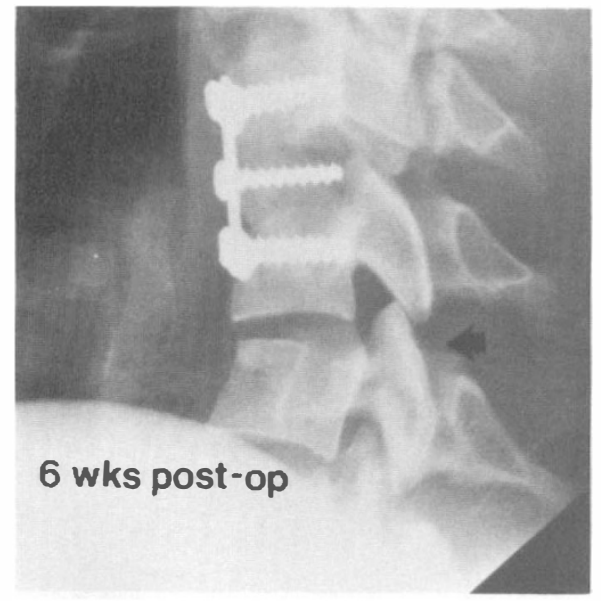

B

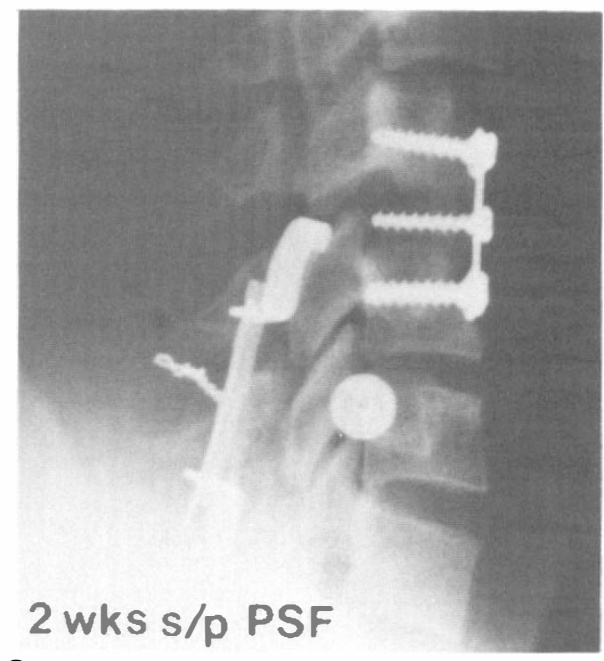

C

Figure 3A, 3B, and 3C A. Initial post-injury radiograph. B. Six weeks post C4-5 anterior spinal fusion. C. Immediate post-operative posterior fusion over $\mathrm{C} 5,6$, and 7. 
procedure. One patient had 2 broken screws (noted at 9 month follow-up), which did not affect the clinical or radiographic result. In this patient, the plate spanned 3 vertebrae, but the fusion was limited to only 2 vertebrae (one involved motion segment).

Three patients (19\%) required a second operation. One patient (Figs 3A-C) had a second procedure within $2 \frac{1}{2}$ months because of an unrecognised posterior injury one level below the involved anterior motion segment. This patient was ultimately stabilised posteriorly with clamp fixation and fusion. The second patient had the plate removed 9 months after the operation because it was broken and possibly causing dysphagia. In this patient, the plate spanned two motion segments ( 3 vertebrae), but only one motion segment ( 2 vertebrae) had been fused. The plate

A

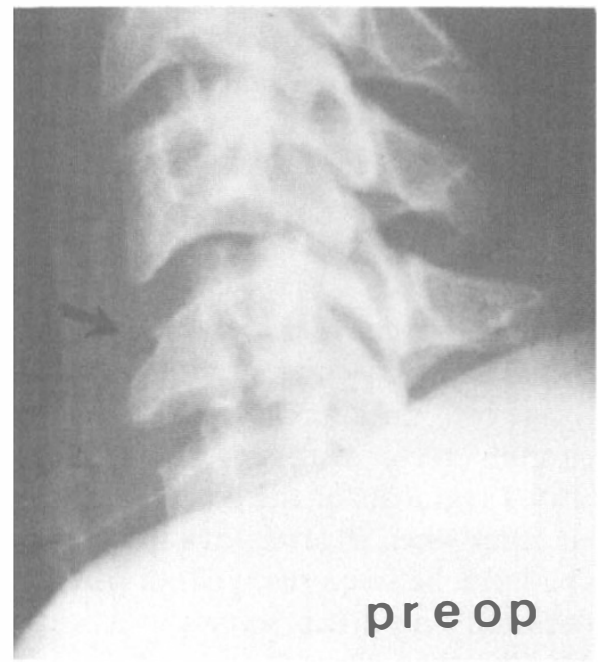

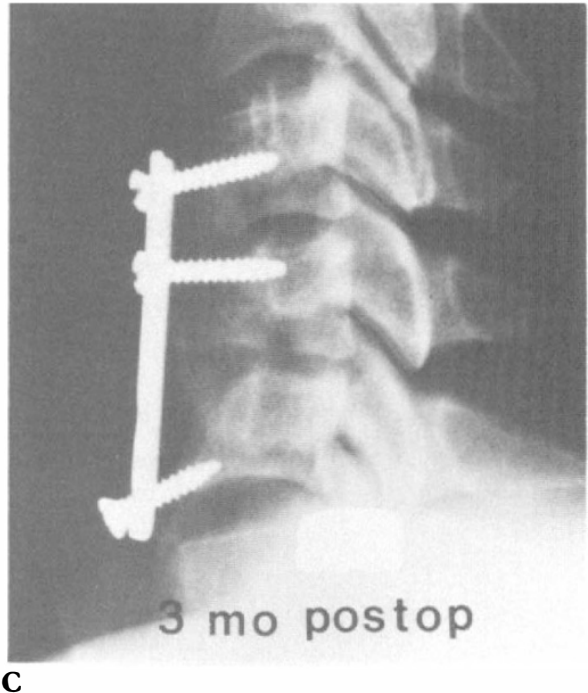
B

\section{3 days postop}

Figure 4, 4B, and 4C A. Initial post-injury radiograph. B. Three days post-surgery \# 1. C. Three days post-surgery \#2. 
failed at the junction of the fused and unfused motion segments. The third patient had a second operation because the superior portion of the graft dislodged in the immediate post operative period (Figs $4 \mathrm{~A}-\mathrm{C}$ ).

\section{Discussion}

Anterior decompression, plate fixation, and fusion of cervical spine injuries have been advocated in a number of studies (Gassman, 1983; Bremer, 1983; Bohler, 1980; de Oliveira, 1987). Earlier studies of anterior cervical fusion did not evaluate radiographic results with the measurement techniques used in this study. These measurements allowed us to critically examine the quality and maintenance of reduction achieved.

Similarly, earlier studies only classified the injuries into three broad categories: Flexion, extension, and vertical compression (Durbin, 1957; Whitley, 1960) and did not classify the injuries according to Allen et al. (1982). We believe that Allen's (1982) classification scheme more accurately describes the various types of cervical spine injuries. In this study, we analysed only unstable injuries, and we believe that by excluding injuries and by utilising the measurement criteria described above, we have achieved a more objective analysis of the results of anterior plate fixation.

Although in vitro studies have shown that the most secure fixation for the anterior screw-plate construct is obtained with bicortical purchase of the screws (Caspar, 1984), no reports advocate bicortical purchase because of the potential risks of spinal cord injury. In this study, plate breakage occurred only in those patients where the plate spanned unfused segments of the spine 6 to 9 months post-operatively; these problems did not occur when all levels encompassed by the plate were fused. No correlation could be made between the types of plates and subsequent failure. Graft dislodgement occurred only when screws were secured mainly in the disc space (Fig. 4B). Specifically, the technical errors made early in the series were: (1) screws placed in disc spaces and not in bone, and (2) plates spanning motion segments that had not been fused. Although the complication rate (25\%) was similar to other studies that have reported results of this technique (Brown, 1988; Van Peteghem, 1979) (Table II), it is appreciably higher than the 6 to $10 \%$ rate of complications reported for posterior procedures (Rogers, 1957; Capen, 1985). However, we believe this anterior technique is indicated for compressive flexion injuries, as shown by Cabanela et al. (1988). Currently, the Synthes cervical $\mathrm{H}$ plate is used for fixation. Although reductions achieved in the distractive flexion

Table II Complications with anterior cervical fusion

\begin{tabular}{lr}
\hline & Per cent \\
\hline Brown & 31 \\
Cabanela & 3 \\
Van Peteghem & 29 \\
de Oliveira & 3 \\
Mann & 25 \\
\hline
\end{tabular}


injuries in this series were maintained, posterior cervical fusion is the treatment of choice for this type of injury.

Multilevel, non-contiguous injuries of the cervical spine have been reported in 7 to $24 \%$ of individuals with cervical injuries (Hadden, 1985). Thus, careful assessment of the cervical spine should be performed before selecting either an anterior or posterior approach. Computerised tomography and/or magnetic resonance imaging may be necessary for this assessment. However, standard lateral radiographs that show all seven cervical vertebrae and the cervicothoracic junction provide the most accurate survey of the cervical spine. Although the non-contiguous injury in the patient in this series necessitated an additional posterior procedure, Hadden et al. (1985) concluded that multilevel cervical spine injuries rarely do need surgery.

\section{Summary}

Anterior decompression and plating provides a method of stabilisation of traumatic injuries of the cervical spine. Neurologic status did not deteriorate in any patient. Solid fusions were achieved in all cases, and the observed complications appear avoidable. Screw loosening and plate breakage should be anticipated if the plate spans unfused segments of the spine. We do not recommend plating unfused motion segments.

\section{References}

Allen BL, Ferguson RL, Lehmann TR, O'Brien RP 1982 A mechanistic classification of closed, indirect fractures and dislocations of the lower cervical spine. Spine 7:1-26.

BAILEY RW, BRADLEY CE 1960 Stabilization of the cervical spine by anterior fusion. Fournal of Bone and Foint Surgery 42A:565-594.

BEDBROOK GM 1966 Pathological principles in the management of spinal cord trauma. Paraplegia 4: 43-57.

BOHLER J, GAUDERNALE T 1980 Anterior plate stabilization for fracture-dislocations of the lower cervical spine. Fournal of Trauma 20:203-205.

BREMER AM, NGUYEN TO 1983 Internal metal plate fixation combined with anterior interbody fusion in cases of cervical spine injury. Neurosurgery 12:649-653.

Brown JA, Havel P, Ebraheim N, Greenblatt SH, Jackson WT 1988 Cervical stabilization by plate and bone fusion. Spine 13:236-240.

Cabanela ME, Ebersold MJ 1988 Anterior plate stabilization for bursting teardrop fractures of the cervical spine. Spine 13:888-891.

CAPEN DA, GARLAND DE, WATERS RL 1985 Surgical stabilization of the cervical spine: A comparative analysis of anterior and posterior spine fusions Clinical Orthopaedics 196:229-237.

CASPAR W 1984 Anterior cervical fusion and interbody stabilization with the trapezial osteosynthetic plate technique. Aesculap-Wissewscheftliche Informationen im Selbstverlag der Aesculap-Werke AG, D-7200, Tuttlingen.

CHESHIRE DJE 1969 The stability of the cervical spine following the conservative treatment of fractures and fracture- dislocations. Paraplegia 7:193-203.

CLOWARD RB 1958 The anterior approach for removal of the ruptured cervical disc. Fournal of Neurosurgery 15:602-617.

ClowARD RB 1969 Surgical treatment of dislocations and compression fractures of the cervical spine by the anterior approach. In: Proceedings of the seventeenth Veterans Administration Spinal Cord Injury Conference. pp. 26-40.

DE OLIVEIRA JC 1987 Anterior plate fixation of traumatic lesions of the lower cervical spine. Spine 12: 324-329.

DiCKSON JH, HARRINGTON PR, ERWIN WD 1978 Results of reduction and stabilization of the severely fractured thoracic and lumbar spine. Fournal of Bone and Foint Surgery 60A:779-805.

DURBIN FC 1957 Fracture-dislocations of the cervical spine. Fournal of Bone and Foint Surgery 39B: 23-28. 
GaSSMAN S, SELGISON D 1983 The anterior cervical plate. Spine 8:700-707.

HADDEN WA, GILLESPIE WJ 1985 Multiple level injuries of the cervical spine. Injury 16:628-633.

MYERS PW, BUCKLEY RD 1967 Management of the complications of anterior cervical fusion. In:

Proceedings of the Sixteenth Veterans Administration Spinal Cord Injury Conference pp. 33-38.

RoBINSON RA, SMITH GW 1958 The treatment of certain cervical spine disorders by anterior removal of intervertebral disc and interbody fusion. Fournal of Bone and Foint Surgery 40A:607-624.

ROGERS WA 1957 Fractures and dislocations of the cervical spine. An end result study. Fournal of Bone and Foint Surgery 39A:341-376.

STAUFFER ES, KELLEY EG 1977 Fracture-dislocations of the cervical spine. Fournal of Bone and Foint Surgery 59A:45-48.

VAN PETEGHEM PK, SCHWEIGEL JF 1979 The fractured cervical spine rendered unstable by anterior cervical fusion. Fournal of Trauma 19:110-114.

White AA, Southwick WO, Punjabi MM 1976 Clinical instability in the lower cervical spine. Spine 1:15-32.

WhITLEY JE, FoRSYTH HF 1960 The classification of cervical spine injuries. American fournal of Roentgenology 83:633-644. 